\title{
A synthetic bispecific antibody capable of neutralizing SARS-CoV-2 Delta and
}

\section{Omicron}

Tom Z. Yuan ${ }^{1}$, Carolina Lucas², Valter S. Monteiro², Akiko Iwasaki², ${ }^{2}$, Marisa L.

Yang ${ }^{1}$, Hector F. Nepita ${ }^{1}$, Ana G. Lujan Hernandez ${ }^{1}$, Joseph M. Taft ${ }^{4}$, Lester Frei ${ }^{4}$,

Sai T. Reddy ${ }^{4}$, Cédric R. Weber ${ }^{5}$, Kevin P. Malobisky ${ }^{6}$, Rodrigo Mesquita ${ }^{6}$, Aaron

K. Sato ${ }^{1, *}$

${ }^{1}$ Twist Biopharma, Twist Bioscience, South San Francisco, CA, USA

${ }^{2}$ School of Medicine, Yale University, New Haven, CT, USA

${ }^{3}$ Howard Hughes Medical Institute, Chevy Chase, MD, USA

${ }^{4}$ Department of Biosystems Science and Engineering, ETH Zurich, Basel, Switzerland

${ }^{5}$ Alloy Therapeutics, Basel, Switzerland

${ }^{6}$ Revelar Biotherapeutics, Inc., Bethesda, MD, USA

*To whom correspondence should be addressed:

Aaron Sato, Email: asato@,twistbioscience.com 


\section{A synthetic bispecific antibody capable of neutralizing SARS-CoV-2 Delta and}

\section{Omicron}

Bispecific antibodies have emerged as a promising strategy for curtailing severe acute respiratory syndrome coronavirus 2 (SARS-CoV-2) immune escape. This brief report highlights RBT-0813 (also known as TB493-04), a synthetic, humanized, receptor-binding domain (RBD)-targeted bispecific antibody that retains picomolar affinity to the Spike (S) trimers of all major variants of concern and neutralizes both SARS-CoV-2 Delta and Omicron in vitro.

Keywords: VHH; SARS-CoV-2; COVID-19; Delta; Omicron; synthetic; bispecific; Spike

\section{Introduction}

Since its emergence in December 2019, SARS-CoV-2 continues to evolve substantially, acquiring sets of mutations that enhance the virus's potency, transmissibility, infectivity, and ability to escape natural and acquired immunity. ${ }^{1}$ Virtually all of these fitness-enhancing mutations are found in Spike (S), the protein through which SARS-CoV-2 binds to angiotensin-converting enzyme 2 (ACE2) on the host cell surface during infection. The receptor-binding domain (RBD) of $\mathrm{S}$ is the primary target of neutralizing antibodies produced after natural infection or vaccination against SARS-CoV-2; this fact has fuelled speculation that SARS-CoV-2 could escape natural and acquired immunity through mutations in the $S .^{2}$ Several variants of concern possessing mutations in the RBD have displayed varying degrees of immune escape, including the Beta (B.1.351), Gamma (P.1) and Delta (B.1.617.2) variants. ${ }^{3-6}$ The recently detected Omicron (B.1.1.529) variant, which possesses at least 30 amino acid mutations in $\mathrm{S}$ alone, ${ }^{7}$ is particularly concerning, as early reports show clear reductions in the efficacy of current therapeutics, including those monoclonal antibody cocktails with Emergency Use Authorization, as well as the commonly used two-dose mRNA vaccine regimens. ${ }^{8-21}$ SARS-CoV-2 escape mutations in the RBD presents a particular risk for recently developed neutralizing antibody therapeutics and endangers ongoing public health responses, thus underscoring the need for new therapeutic approaches, such as multivalent antibodies, which have recently been shown to potentiate SARS-CoV-2 neutralization and reduce immune escape when compared to monovalent antibodies. ${ }^{22-26}$ Because the Delta and Omicron variants account for $99.7 \%$ of cases in the United States (as of December 25, 2021 27 ), a bispecific antibody capable of binding and neutralizing both variants would represent a therapeutic and public health advantage over currently available treatment modalities. 
In this paper, we highlight RBT-0813, a synthetic VHH bispecific antibody capable of binding and neutralizing the SARS-CoV-2 Delta and Omicron variants. This bispecific antibody links together two humanized VHH antibodies - TB202-03 and TB339-031 — with constant heavy chain 2 (CH2) and 3 (CH3) Fc domains (Figure 1). TB202-03, which was discovered by panning the TB202 VHH library ${ }^{28}$ against the S1 monomer of the SARS-CoV-2 WA1 strain, has been shown to effectively neutralize pseudoviruses encoding the Alpha, Beta, and Gamma S proteins, but not those encoding L452R-bearing S protein variants such as Delta and Epsilon (B.1.429). TB339-031 was discovered by panning the TB201 VHH library ${ }^{28}$ against the Beta S1 (subdomain of S) and was found to bind and neutralize L452R-bearing S protein variants. Here, we describe the biophysical and functional characterization of the bispecific RBT-0813 antibody, focusing on its binding and neutralization of Delta and Omicron variants.

\section{Results}

\section{RBT-0813 binds SARS-CoV-2 Delta and Omicron with picomolar affinity}

RBT-0813 was constructed from lead VHH antibodies discovered in biopanning campaigns against the ancestral (TB202-03) and Beta (TB339-031) S proteins. To create a broadly neutralizing antibody, we combined leads TB202-03 and TB339-031 into a single bispecific construct.

Screening by surface plasmon resonance (SPR) revealed picomolar apparent binding affinities between RBT-0813 and the prefusion-stabilized S trimers of the Alpha, Beta, Delta, Gamma, Kappa (B.1.617.1), and Omicron variants (Figure 2a, Table 1). SPR traces obtained with TB20203 and TB339-031 showed which of the two contributed to RBT-0813's binding to each S trimer. Although TB202-03 bound to the Alpha, Beta, Gamma, Kappa with the same affinity as the ancestral S trimer, it displayed reduced (yet still picomolar) affinities with the Kappa and Delta variants (Figure 2a, Table 1). By contrast, TB339-031 bound every S trimer variant with low picomolar affinities except the Omicron variant (Figure 2a, Table 1). Fortuitously, TB202-03 displayed low picomolar affinity to the S trimer of Omicron, as did RBT-0813. SPR experiments performed using variant S1 monomers showed the same patterns, although apparent binding affinities were in the nanomolar range (Figure 2a). These data agree with previous biophysical and functional characterizations of TB202-03 ${ }^{28}$ (CoVIC-094 in Hastie et al. ${ }^{29}$ ) that showed reduced activity of TB202-03 against S proteins bearing the L452R mutation (namely, Delta and Epsilon).

Consistent with the SPR data described above, TB202-03 and RBT-0813, but not TB339031, bound the Omicron S1 RBD displayed on the surface of yeast, as measured by flow cytometry 
(Figure 2b); thus providing independent confirmation that TB202-03 mediates the Omicron binding of RBT-0813.

\section{RBT-0813 potently neutralizes SARS-CoV-2 Delta and Omicron}

According to early reports, the vast majority of monoclonal antibodies in development fail to neutralize Omicron, including antibodies that effectively neutralize Delta. ${ }^{9,18,19}$ Similarly, the U.S. Food and Drug Administration (FDA) has recently updated the fact sheets for health care providers for the EUA of antibody therapies from Eli Lilly ${ }^{33}$ (cocktail of two monoclonal antibodies: bamlanivimab and etesevimab) and Regeneron Pharmaceuticals ${ }^{34}$ (cocktail of two monoclonal antibodies: casirivimab and imdevimab). In both of these cases, in vitro binding and neutralization studies have suggested that neither of the antibody cocktail therapies are likely to have clinical efficacy against the Omicron variant. To assess the neutralization potential of RBT0813, we utilized authentic viruses isolated from nasopharyngeal specimens of patients in plaque reduction neutralization assays to determine whether RBT-0813 can neutralize SARS-CoV-2 Ancestral, Delta and Omicron. As shown in Figure 3, RBT-0813 neutralizes authentic Delta and Omicron at half maximal effective concentrations (EC50) of 521.1 and $713.6 \mathrm{ng} / \mathrm{ml}$, respectively. In line with the binding data, RBT-0813 neutralizes Delta and Omicron through either the TB339031 and TB202-03 VHH antibodies, respectively. These values are comparable to those obtained with sotrovimab (VIR-7831), one of the few monoclonal antibodies that shows effective neutralization against both Delta and Omicron at 325 and $917 \mathrm{ng} / \mathrm{ml}$, respectively. ${ }^{18}$ In a separate study, sotrovimab neutralized Ancestral and Omicron at 179 and $320 \mathrm{ng} / \mathrm{ml}$, respectively. ${ }^{9}$ Interestingly, RBT-0813 neutralizes Ancestral SARS-CoV-2 at EC50 of $104.4 \mathrm{ng} / \mathrm{mL}$, which is approximately 5-fold and 7-fold enhanced compared to Delta and Omicron, respectively. Since TB202-03 and TB339-031 both bind Ancestral SARS-CoV-2 with high affinity, they avidly work together to neutralize in concert with one another. 


\section{Discussion}

First detected in November 2021, the Omicron variant has quickly spread worldwide, causing infections in at least 89 countries. ${ }^{30}$ Omicron's rapid transmission and sheer number of S mutations, especially in the RBD, quickly sparked concerns about the variant and its ability to escape immune protection and existing antibody therapeutics. Moreover, despite Omicron's meteoric rise, with its displacement of Delta in some areas, Delta remains a major threat to public health, especially because early animal studies indicate that Delta causes more severe disease than Omicron. ${ }^{31}$ In this report, we show that RBT-0813 binds and neutralizes not only Delta, which has only recently begun to lose its foothold as the dominant global strain, but importantly, it binds and neutralizes Omicron as well. With this report, RBT-0813 represents one of the few reported Abs that retain significant antiviral activity against Omicron.

Most of the mAbs that have been shown to neutralize Omicron target conserved Sarbecovirus epitopes and do not compete with ACE2 for S binding. ${ }^{9,18,19}$ Although the mechanism through which RBT-0813 neutralizes Omicron has not yet been clarified, the TB202-03 arm presumably contributes more than the TB339-031 arm due to its higher affinity to the Omicron S1 monomer and S trimer (Figure 2a). In stark contrast to antibodies that target a highly conserved Sarbecovirus epitope (e.g., sotrovimab), TB202-03 binds toward the outer edge of the receptorbinding motif of SARS-CoV-2 (the RBD-4 community in Hastie et al. ${ }^{29}$ ), does not bind SARSCoV S1, and competes with ACE2 for SARS-CoV-2 S binding. ${ }^{28}$ The antiviral activity of RBT0813 may be explained by the fact that none of the key residues in the TB202-03 epitope namely, N450, I472, and F49028 — are mutated in Omicron.

In aggregate, these early data highlight RBT-0813 as a promising, innovative bispecific VHH therapeutic candidate for further development in the ongoing SARS-CoV-2 pandemic. 
bioRxiv preprint doi: https://doi.org/10.1101/2022.01.04.474803; this version posted January 4,2022 . The copyright holder for this preprint (which was not certified by peer review) is the author/funder, who has granted bioRxiv a license to display the preprint in perpetuity. It is made available under aCC-BY-NC-ND 4.0 International license.

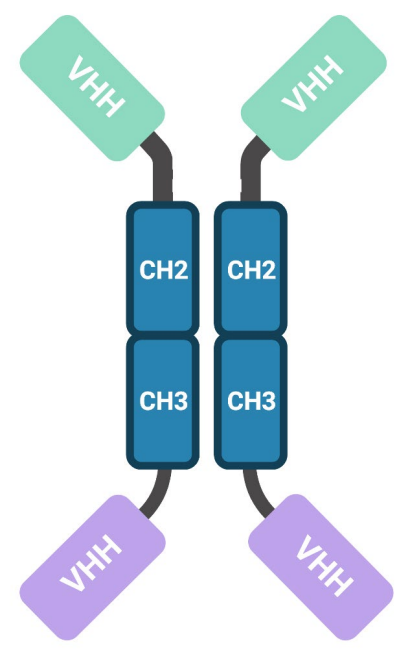

Figure 1. Schematic of RBT-0813, a synthetic bispecific antibody. Green, TB202-03; purple, TB339-031; blue, Fc domains. 
bioRxiv preprint doi: https://doi.org/10.1101/2022.01.04.474803; this version posted January 4 , 2022. The copyright holder for this preprint

(which was not certified by peer review) is the author/funder, who has granted bioRxiv a license to display the preprint in perpetuity. It is made available under aCC-BY-NC-ND 4.0 International license.

$\mathbf{a}$

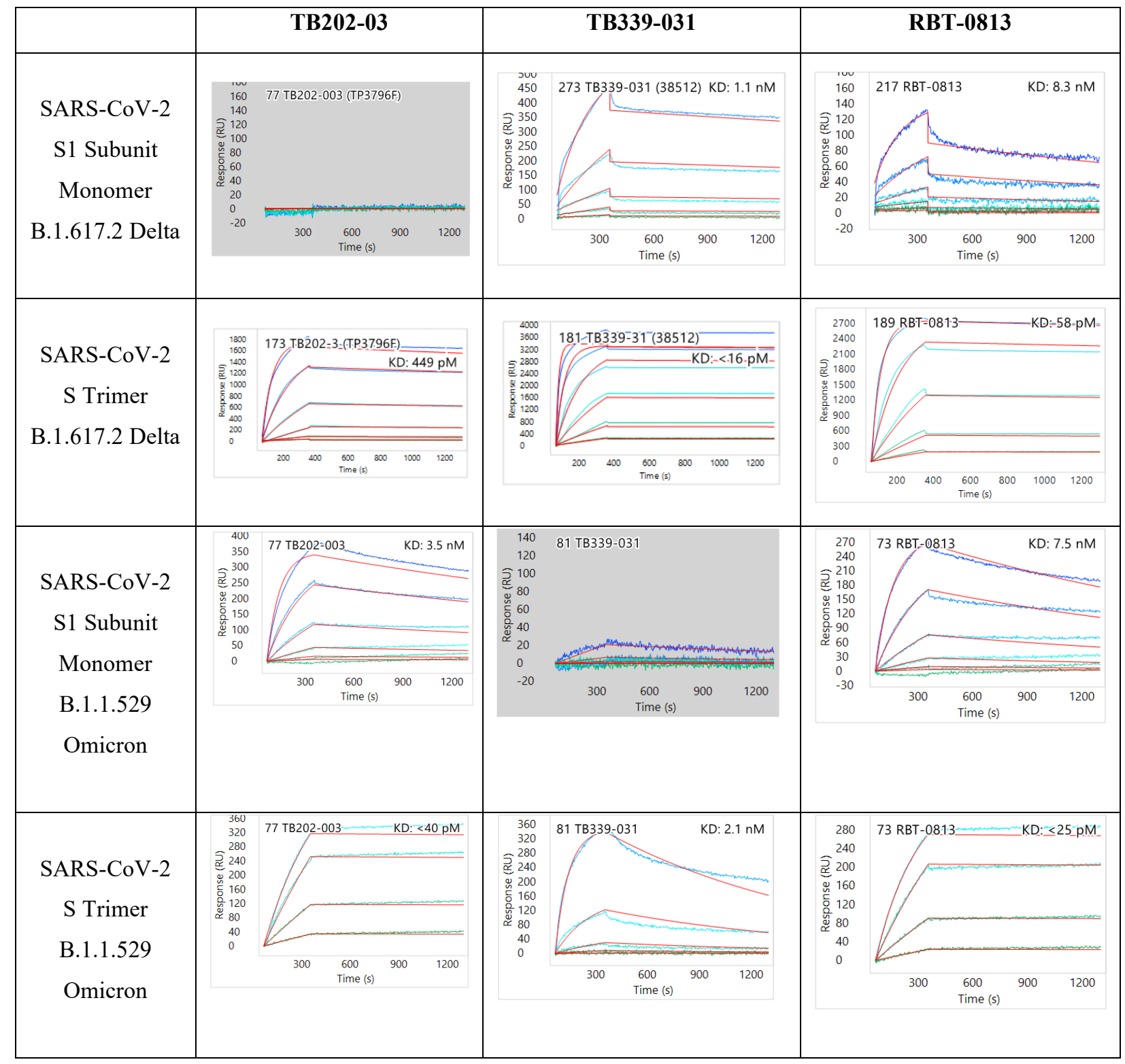

TB202-03

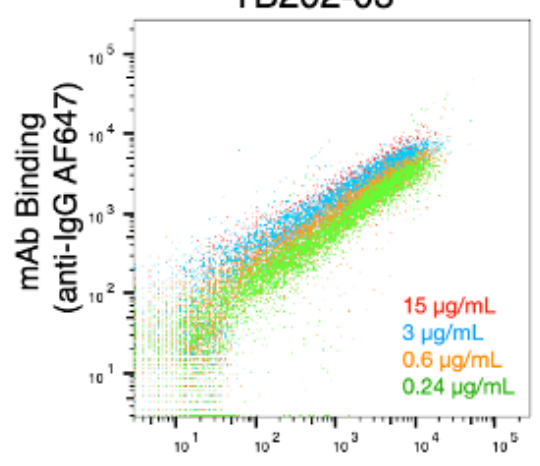

TB339-031

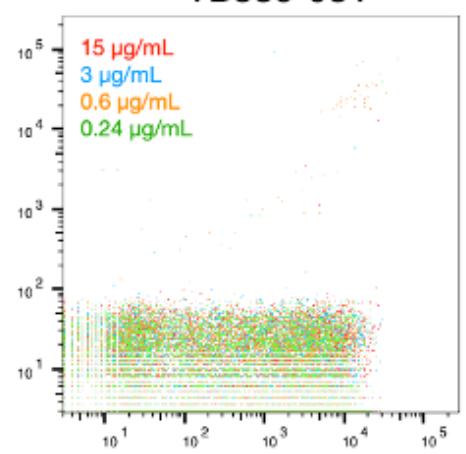

RBT-0813

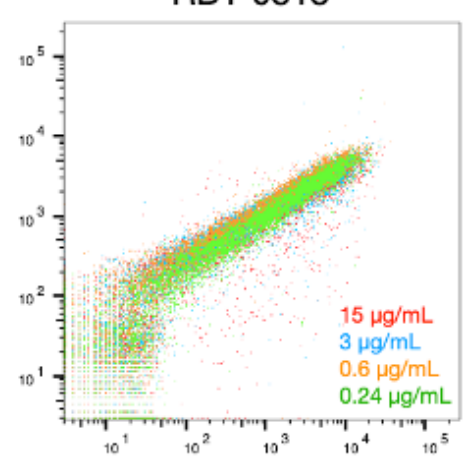

Surface RBD Display (FLAG-PE) 


\section{Figure 2. Biophysical characterization of TB493-04 (RBT-0813) and its parental constructs}

TB202-03 and TB339-031. (a) SPR traces of TB202-03, TB339-031, and RBT-0813 binding to the S1 monomers and S trimers of SARS-CoV-2 Delta and Omicron. (b) Binding of RBT-0813 to Omicron S1 RBD displayed on the surface of yeast. Binding of Omicron S1 RBD by RBT-0813 is confirmed by high fluorescence in both channels. 


\begin{tabular}{|c|c|c|c|c|c|c|c|c|c|c|c|c|}
\hline \multirow[b]{2}{*}{ Antibody } & \multicolumn{3}{|c|}{ SARS-CoV-2 S Trimer (WA1) } & \multicolumn{3}{|c|}{ SARS-CoV-2 S Trimer (Alpha) } & \multicolumn{3}{|c|}{ SARS-CoV-2 S Trimer (Beta) } & \multicolumn{3}{|c|}{ SARS-CoV-2 S Trimer (Gamma) } \\
\hline & $k_{\mathrm{a}}(\mathrm{M}-1 \mathrm{~s}-1)$ & $k_{\mathrm{d}}(\mathrm{s}-1)$ & $K_{\mathrm{D}}(\mathrm{M})$ & $k_{\mathrm{a}}(\mathrm{M}-1 \mathrm{~s}-1)$ & $k_{\mathrm{d}}(\mathrm{s}-1)$ & $K_{\mathrm{D}}(\mathrm{M})$ & $k_{\mathrm{a}}(\mathrm{M}-1 \mathrm{~s}-1)$ & $k_{\mathrm{d}}(\mathrm{s}-1)$ & $K_{\mathrm{D}}(\mathrm{M})$ & $k_{\mathrm{a}}(\mathrm{M}-1 \mathrm{~s}-1)$ & $k_{\mathrm{d}}(\mathrm{s}-1)$ & $K_{\mathrm{D}}(\mathrm{M})$ \\
\hline $\begin{array}{l}\text { TB202-3 } \\
\text { (VHH) }\end{array}$ & $5.33 \mathrm{E}+04$ & $1.00 \mathrm{E}-05^{*}$ & $1.87 \mathrm{E}-10$ & $7.02 \mathrm{E}+04$ & $1.00 \mathrm{E}-05^{*}$ & $1.43 \mathrm{E}-10$ & $1.07 \mathrm{E}+05$ & $1.00 \mathrm{E}-05^{*}$ & $9.38 \mathrm{E}-11$ & $9.42 \mathrm{E}+04$ & $1.20 \mathrm{E}-05$ & $1.28 \mathrm{E}-10$ \\
\hline $\begin{array}{l}\text { TB339-031 } \\
\text { (VHH) }\end{array}$ & $6.00 \mathrm{E}+05$ & $1.00 \mathrm{E}-05^{*}$ & $1.42 \mathrm{E}-11$ & $6.99 \mathrm{E}+05$ & $1.00 \mathrm{E}-05^{*}$ & $1.43 \mathrm{E}-11$ & $8.51 \mathrm{E}+05$ & $1.00 \mathrm{E}-05^{*}$ & $1.17 \mathrm{E}-11$ & $8.34 \mathrm{E}+05$ & $1.00 \mathrm{E}-05^{*}$ & $1.20 \mathrm{E}-11$ \\
\hline $\begin{array}{c}\text { RBT- } 0813 \\
\text { (bispecific) }\end{array}$ & $2.85 \mathrm{E}+05$ & $1.00 \mathrm{E}-05^{*}$ & $3.51 \mathrm{E}-11$ & $1.74 \mathrm{E}+05$ & $1.00 \mathrm{E}-05^{*}$ & $5.74 \mathrm{E}-11$ & $2.66 \mathrm{E}+05$ & $1.00 \mathrm{E}-05^{*}$ & $3.76 \mathrm{E}-11$ & $2.97 \mathrm{E}+05$ & $1.00 \mathrm{E}-05^{*}$ & 3.37E-11 \\
\hline & SARS-C & -2 S Trim & (appa) & SARS- & V-2 S Trim & Delta) & SARS-C & $-2 \mathrm{~S}$ Trimer & micron) & & & \\
\hline Antibody & $k_{\mathrm{a}}(\mathrm{M}-1 \mathrm{~s}-1)$ & $k_{\mathrm{d}}(\mathrm{s}-1)$ & $K_{\mathrm{D}}(\mathrm{M})$ & $k_{\mathrm{a}}(\mathrm{M}-1 \mathrm{~s}-1)$ & $k_{\mathrm{d}}(\mathrm{s}-1)$ & $K_{\mathrm{D}}(\mathrm{M})$ & $k_{\mathrm{a}}(\mathrm{M}-1 \mathrm{~s}-1)$ & $k_{\mathrm{d}}(\mathrm{s}-1)$ & $K_{\mathrm{D}}(\mathrm{M})$ & & & \\
\hline $\begin{array}{c}\text { TB202-3 } \\
\text { (VHH) }\end{array}$ & $1.45 \mathrm{E}+05$ & $8.17 \mathrm{E}-05$ & $5.62 \mathrm{E}-10$ & $1.58 \mathrm{E}+05$ & $7.08 \mathrm{E}-05$ & $4.49 \mathrm{E}-10$ & $2.53 \mathrm{E}+05$ & $1.00 \mathrm{E}-05^{*}$ & $3.95 \mathrm{E}-11$ & & & \\
\hline $\begin{array}{l}\text { TB339-031 } \\
\text { (VHH) }\end{array}$ & $7.77 \mathrm{E}+05$ & $1.00 \mathrm{E}-05^{*}$ & $1.29 \mathrm{E}-11$ & $6.18 \mathrm{E}+05$ & $1.00 \mathrm{E}-05^{*}$ & $1.62 \mathrm{E}-11$ & $3.79 \mathrm{E}+05$ & 7.82E-04 & $2.06 \mathrm{E}-09$ & & & \\
\hline $\begin{array}{l}\text { RBT-0813 } \\
\text { (bispecific) }\end{array}$ & $3.28 \mathrm{E}+05$ & $6.09 \mathrm{E}-05$ & $1.86 \mathrm{E}-10$ & $5.85 \mathrm{E}+05$ & $3.42 \mathrm{E}-05$ & $5.83 \mathrm{E}-11$ & $3.98 \mathrm{E}+05$ & $1.00 \mathrm{E}-05^{*}$ & $2.52 \mathrm{E}-11$ & & & \\
\hline
\end{tabular}

Table 1. Apparent binding affinity summary of TB493-04 (RBT-0813) and its parental constructs TB202-03 and TB339-031 to $S$ glycoprotein prefusion trimers as measured by

SPR. Data were analyzed in Carterra's Kinetics Tool software with 1:1 binding model. *Indicates off-rate is slower than limit of detection. 


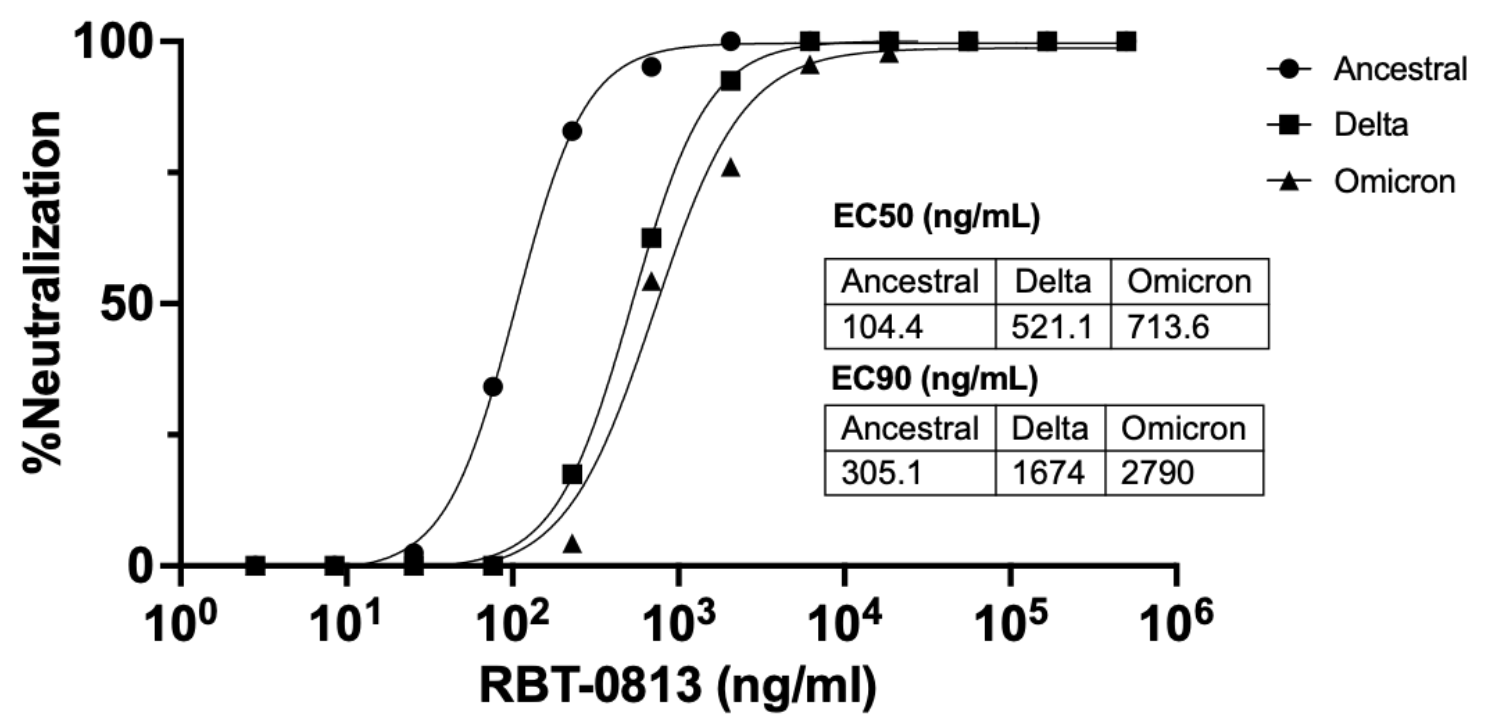

Figure 3. Neutralization of authentic SARS-CoV-2 Delta and Omicron by RBT-0813.

Neutralization curves against ancestral lineage A virus (WA1,USA), Delta and Omicron SARS-

CoV-2 variants. Antibody-mediated neutralization was accessed by SARS-CoV-2 infection on

TMPRSS2-VeroE6 cells. EC50 and EC90 values represent the concentrations required to reduce the number of plaques by $50 \%$ and $90 \%$, respectively. Representative curves of three independent experiments with technical duplicates. 


\section{Materials and Methods}

\section{SPR affinity measurements}

SPR experiments were performed on a Carterra LSA SPR biosensor equipped with a $\mathrm{HC} 30 \mathrm{M}$ chip at $25^{\circ} \mathrm{C}$ in HBS-TE. Antibodies were diluted to $10 \mu \mathrm{g} / \mathrm{mL}$ and amine-coupled to the sensor chip by EDC/NHS activation, followed by ethanolamine $\mathrm{HCl}$ quenching. Increasing concentrations of analyte were flowed over the sensor chip in HBS-TE with $0.5 \mathrm{mg} / \mathrm{mL}$ BSA with 5 minute association and 15 minute dissociation. SARS-CoV-2 protein reagents were sourced commercially from Acro Biosystems: S1 B.1.1.529 Omicron (S1N-C52Ha), S Trimer B.1.1.529 Omicron (SPN-C52Hz), S1 B.1.617.2 Delta (S1N-C52Hu), S Trimer B.1.617.2 Delta (SPNC52He), S Trimer WA1 (Acro SPN-C52H9), S Trimer B.1.1.7 Alpha (Acro SPN-C52H6), S Trimer B.1.351 Beta (Acro SPN-C52Hk), S Trimer P.1 Gamma (Acro SPN-C52Hg) and S Trimer B.1.617.1 Kappa (Acro SPN-C52Hr). Following each injection cycle, the surface was regenerated with $2 \times 30$-second injections of IgG elution buffer (Thermo). Data were analyzed in Carterra's Kinetics Tool software with 1:1 binding model.

\section{Flow binding assay}

\section{Growth/induction}

EBY100 yeast cells transformed with pYD1-Omicron RBD (amino acids 331-531) were picked from a selective plate and inoculated in $1 \mathrm{~mL}$ SD-UT medium [yeast nitrogen basecasamino acids (YNB-CAA) (BD Biosciences 223120) + 2\% D-(+)-Glucose (Sigma G5767-500G) growth medium including phosphate buffer $\left(5.4 \mathrm{~g} / 1 \mathrm{Na}_{2} \mathrm{HPO}_{4}, 8.6 \mathrm{~g} / 1 \mathrm{NaH}_{2} \mathrm{PO}_{4} \cdot \mathrm{H}_{2} \mathrm{O}\right)$ and $1 \mathrm{X}$ Penicillin-Streptomycin]. The cultures were incubated for $12-18 \mathrm{~h}$ at $30^{\circ} \mathrm{C}$ and 250 RPM. $2 \times 10^{7}$ cells were pelleted by centrifugation for $30 \mathrm{~s}$ at $8,000 \mathrm{x}$. The pellets were resuspended in $1 \mathrm{~mL}$ SG-UT [(YNB-CAA) (BD Biosciences 223120) + 2\% D-(+)-Galactose (Sigma G0625-500G) induction medium including phosphate buffer (5.4 g/l Na2HPO4, 8.6 g/1 NaH2PO4·H2O) and 1X Penicillin-Streptomycin]. The induction cultures were incubated for $32-40 \mathrm{~h}$ at $23{ }^{\circ} \mathrm{C}$ and 250 RPM.

\section{Staining}

$6 \times 10^{5}$ cells were added into the wells of a 96 well filter plate (MSHVS4510 Millipore MultiScreenHTS HV Filter Plate, $0.45 \mu \mathrm{m}$, clear, sterile). Each of the 3 constructs (TB202-03, TB339-031, and RBT-0813) were diluted to final concentrations with DPBS $+0.5 \%$ BSA $+2 \mathrm{mM}$ 
EDTA $+0.1 \%$ Tween $20.20 \mu \mathrm{L}$ of mAb solution was added to the cells in the filter wells and the cells were incubated for $1 \mathrm{~h}$ at $4{ }^{\circ} \mathrm{C}$ and $750 \mathrm{RPM}$ on a thermomixer (Eppendorf, ThermoMixer C). After the incubation, the liquid in the plate was removed using a vacuum manifold. The pressure was kept at $<5$ bar. To wash the cells, $200 \mu \mathrm{L}$ DPBS $+0.5 \%$ BSA $+2 \mathrm{mM}$ EDTA $+0.1 \%$ Tween20 was added to each well and subsequently removed using the vacuum manifold.

$20 \mu \mathrm{L}$ anti-IgG AlexaFluorophore $647 \mathrm{mAb}(5 \mu \mathrm{g} / \mathrm{mL}$ ) (Jackson Immunoresearch 109-605098) was added to the cells and they were incubated for $45 \mathrm{~min}$ at $4{ }^{\circ} \mathrm{C}$ and $750 \mathrm{RPM}$ on a thermomixer (Eppendorf, ThermoMixer C). The liquid in the plate was removed using a vacuum manifold, and the wash step was repeated.

For the expression staining, $20 \mu \mathrm{L}$ anti-FLAG PE mAb $(1 \mu \mathrm{g} / \mathrm{mL})$ (Biolegend 637309) was added to the cells and they were incubated for $30 \mathrm{~min}$ at $4{ }^{\circ} \mathrm{C}$ and $750 \mathrm{RPM}$ on a thermomixer (Eppendorf, ThermoMixer C). The liquid in the plate was removed using a vacuum manifold. No wash step was performed. $200 \mu \mathrm{L}$ DPBS $+0.5 \%$ BSA $+2 \mathrm{mM}$ EDTA $+0.1 \%$ Tween 20 was added to each well and the cells were resuspended by repeated pipetting. $20 \mu \mathrm{L}$ of resuspended cells were mixed with $180 \mu \mathrm{L}$ DPBS $+0.5 \%$ BSA $+2 \mathrm{mM}$ EDTA $+0.1 \%$ Tween 20 .

\section{Scanning}

The cells were scanned using a BD Fortessa analyzer equipped with an HTS system. The following lasers and bandpass (BP) filters were used: $561 \mathrm{~nm}$ with a BP filter of 586/15 and 640 $\mathrm{nm}$ with a BP filter of $670 / 14$. For each sample, $10^{4}$ events were measured. The data was analyzed using FlowJo V10.4.2.

\section{SARS-CoV-2 viral culture}

TMPRSS2-VeroE6 kidney epithelial cells were cultured in Dulbecco's Modified Eagle Medium (DMEM) supplemented with $1 \%$ sodium pyruvate (NEAA) and $10 \%$ fetal bovine serum (FBS) at $37^{\circ} \mathrm{C}$ and 5\% CO2. The cell line has been tested negative for contamination with mycoplasma. SARS-CoV-2 ancestral strain, lineage A(USA-WA1/2020), was obtained from BEI Resources (\#NR-52281). Delta and Omicron variants were isolated from nasopharyngeal specimens as previously described ${ }^{32}$. Expanded viruses were re-sequenced following the same method as described above and genome sequences were uploaded to GenBank and the aligned consensus genomes are available on GitHub (https://github.com/grubaughlab/paper_2021_Nab-variants). The pelleted virus was then resuspended in PBS and aliquoted for storage at $-80^{\circ} \mathrm{C}$. Viral titers were 
measured by standard plaque assay using TMPRSS2-VeroE6. All experiments were performed in a biosafety level 3 laboratory with approval from the Yale Environmental Health and Safety office.

\section{Authentic virus neutralization assay}

Serial dilutions of RBT-0813 $(500 \mu \mathrm{g} / \mathrm{ml}$ to $2.89 \mathrm{ng} / \mathrm{ml})$ were individually incubated with the ancestral SARS-CoV-2 strain (USA-WA1/2020), the Delta variant, or Omicron variant, for $1 \mathrm{~h}$ at $37^{\circ} \mathrm{C}$. (Viral concentrations were optimized to generate 60-120 plaques per well.) The resulting mixtures were then applied to TMPRSS2-VeroE6 cells, plated in a 12-well plate, for $1 \mathrm{hr}$, after which MEM supplemented with $\mathrm{NaHCO}_{3}, 4 \% \mathrm{FBS}$, and $0.6 \%$ Avicel, was added to each well. At $40 \mathrm{~h}$ post-infection, cells were fixed with $10 \%$ formaldehyde for $1 \mathrm{~h}$ and then stained with $0.5 \%$ crystal violet to resolve plaques. All experiments were performed in parallel with baseline controls. Analyses of plaque counts were done using GraphPad Prism software, version 8.4.

\section{Competing Interests}

Twist Biopharma paid Alloy Therapeutics/ Department of Biosystems Science and Engineering, ETH Zurich to generate referenced data.

A.S and T.Y. are paid employees and stockholders of Twist Bioscience Corporation that has licensed RBT 0813 for a substantial equity interest in Revelar Biotherapeutics, Inc. and other contingent consideration.

K.M. and R.M. are paid employees and stockholders of Revelar Biotherapeutics., Inc.

A.I. serves as the Co-Chair of Revelar Biotherapeutics, Inc.'s Scientific Advisory Board and is a stockholder.

The other authors declare no competing interests. 


\section{References}

1. Harvey WT, Carabelli AM, Jackson B, Gupta RK, Thomson EC, Harrison EM, Ludden C, Reeve R, Rambaut A, COVID-19 Genomics UK (COG-UK) Consortium, et al. SARS-CoV-2 variants, spike mutations and immune escape. Nat Rev Microbiol 2021; 19:409-24.

2. Williams TC, Burgers WA. SARS-CoV-2 evolution and vaccines: cause for concern? Lancet Respir Med 2021; 9:333-5.

3. Cele S, Gazy I, Jackson L, Hwa S-H, Tegally H, Lustig G, Giandhari J, Pillay S, Wilkinson E, Naidoo Y, et al. Escape of SARS-CoV-2 501Y.V2 from neutralization by convalescent plasma. Nature 2021; 593:142-6.

4. Wang P, Nair MS, Liu L, Iketani S, Luo Y, Guo Y, Wang M, Yu J, Zhang B, Kwong PD, et al. Antibody resistance of SARS-CoV-2 variants B.1.351 and B.1.1.7. Nature 2021; 593:130-5.

5. Planas D, Veyer D, Baidaliuk A, Staropoli I, Guivel-Benhassine F, Rajah MM, Planchais C, Porrot F, Robillard N, Puech J, et al. Reduced sensitivity of SARS-CoV-2 variant Delta to antibody neutralization. Nature 2021; 596:276-80.

6. McCallum M, Walls AC, Sprouse KR, Bowen JE, Rosen LE, Dang HV, De Marco A, Franko N, Tilles SW, Logue J, et al. Molecular basis of immune evasion by the Delta and Kappa SARS-CoV-2 variants. Science $2021 ; 374: 1621-6$.

7. National Center for Immunization and Respiratory Diseases (NCIRD), Division of Viral Diseases. Science Brief: Omicron (B.1.1.529) Variant. In: CDC COVID-19 Science Briefs. Atlanta (GA): Centers for Disease Control and Prevention (US); 2021.

8. Wilhelm A, Widera M, Grikscheit K, Toptan T, Schenk B, Pallas C, Metzler M, Kohmer N, Hoehl S, Helfritz FA, et al. Reduced neutralization of SARS-CoV-2 Omicron variant by vaccine Sera and monoclonal antibodies. bioRxiv 2021; Available from: http://medrxiv.org/lookup/doi/10.1101/2021.12.07.21267432

9. Cameroni E, Bowen JE, Rosen LE, Saliba C, Zepeda SK, Culap K, Pinto D, VanBlargan LA, De Marco A, di Iulio J, et al. Broadly neutralizing antibodies overcome SARS-CoV-2 Omicron antigenic shift. Nature 2021; Available from: https://www.nature.com/articles/d41586-021-03825-4

10. Dejnirattisai W, Shaw RH, Supasa P, Liu C, Stuart AS, Pollard AJ, Liu X, Lambe T, Crook D, Stuart DI, et al. Reduced neutralisation of SARS-CoV-2 omicron B.1.1.529 variant by post-immunisation serum. Lancet 2021; Available from: http://dx.doi.org/10.1016/S0140-6736(21)02844-0

11. Aggarwal A, Stella AO, Walker G, Akerman A, Milogiannakis V, Brilot F, Amatayakul-Chantler S, Roth N, Coppola G, Schofield P, et al. SARS-CoV-2 Omicron: evasion of potent humoral responses and resistance to clinical immunotherapeutics relative to viral variants of concern. bioRxiv 2021; Available from: http://medrxiv.org/lookup/doi/10.1101/2021.12.14.21267772

12. Ai J, Zhang H, Zhang Y, Lin K, Zhang Y, Wu J, Wan Y, Huang Y, Song J, Fu Z, et al. Omicron variant showed lower neutralizing sensitivity than other SARS-CoV-2 variants to immune sera elicited by vaccines after boost. Emerg Microbes Infect 2021; 1-24.

13. Garcia-Beltran WF, St Denis KJ, Hoelzemer A, Lam EC, Nitido AD, Sheehan ML, Berrios C, Ofoman O, Chang CC, Hauser BM, et al. mRNA-based COVID-19 vaccine boosters induce neutralizing immunity against SARS-CoV-2 Omicron variant. medRxiv 2021; Available from: http://dx.doi.org/10.1101/2021.12.14.21267755

14. Doria-Rose NA, Shen X, Schmidt SD, O’Dell S, McDanal C, Feng W, Tong J, Eaton A, Maglinao M, 
Tang H, et al. Booster of mRNA-1273 Vaccine Reduces SARS-CoV-2 Omicron Escape from Neutralizing Antibodies. medRxiv 2021; Available from: http://dx.doi.org/10.1101/2021.12.15.21267805

15. Schmidt F, Muecksch F, Weisblum Y, Silva JD, Bednarski E, Cho A, Wang Z, Gaebler C, Caskey M, Nussenzweig MC, et al. Plasma neutralization properties of the SARS-CoV-2 Omicron variant. medRxiv 2021; Available from: http://dx.doi.org/10.1101/2021.12.12.21267646

16. Lu L, Mok BW-Y, Chen L-L, Chan JM-C, Tsang OT-Y, Lam BH-S, Chuang VW-M, Chu AW-H, Chan W-M, Ip JD, et al. Neutralization of SARS-CoV-2 Omicron variant by sera from BNT162b2 or Coronavac vaccine recipients. Clin Infect Dis 2021; Available from: http://dx.doi.org/10.1093/cid/ciab1041

17. Carreño JM, Alshammary H, Tcheou J, Singh G, Raskin A, Kawabata H, Sominsky L, Clark J, Adelsberg DC, Bielak D, et al. Activity of convalescent and vaccine serum against SARS-CoV-2 Omicron. Nature 2021; Available from: https://www.nature.com/articles/d41586-021-03846-z

18. Planas D, Saunders N, Maes P, Guivel-Benhassine F, Planchais C, Buchrieser J, Bolland W-H, Porrot F, Staropoli I, Lemoine F, et al. Considerable escape of SARS-CoV-2 Omicron to antibody neutralization. Nature 2021; Available from: https://www.nature.com/articles/d41586-021-03827-2

19. Cao Y, Wang J, Jian F, Xiao T, Song W, Yisimayi A, Huang W, Li Q, Wang P, An R, et al. Omicron escapes the majority of existing SARS-CoV-2 neutralizing antibodies. Nature 2021; Available from: https://www.nature.com/articles/d41586-021-03796-6

20. Cele S, Jackson L, Khoury DS, Khan K, Moyo-Gwete T, Tegally H, San JE, Cromer D, Scheepers C, Amoako D, et al. Omicron extensively but incompletely escapes Pfizer BNT162b2 neutralization. Nature 2021; Available from: https://www.nature.com/articles/d41586-021-03824-5

21. Liu L, Iketani S, Guo Y, Chan JF-W, Wang M, Liu L, Luo Y, Chu H, Huang Y, Nair MS, et al. Striking antibody evasion manifested by the Omicron variant of SARS-CoV-2. Nature 2021; Available from: https://www.nature.com/articles/d41586-021-03826-3

22. Koenig P-A, Das H, Liu H, Kümmerer BM, Gohr FN, Jenster L-M, Schiffelers LDJ, Tesfamariam YM, Uchima M, Wuerth JD, et al. Structure-guided multivalent nanobodies block SARS-CoV-2 infection and suppress mutational escape. Science 2021; 371. Available from: http://dx.doi.org/10.1126/science.abe6230

23. Cho H, Gonzales-Wartz KK, Huang D, Yuan M, Peterson M, Liang J, Beutler N, Torres JL, Cong Y, Postnikova E, et al. Bispecific antibodies targeting distinct regions of the spike protein potently neutralize SARS-CoV-2 variants of concern. Sci Transl Med 2021; 13:eabj5413.

24. Wu X, Cheng L, Fu M, Huang B, Zhu L, Xu S, Shi H, Zhang D, Yuan H, Nawaz W, et al. A potent bispecific nanobody protects hACE2 mice against SARS-CoV-2 infection via intranasal administration. Cell Rep 2021; 37:109869.

25. Lim SA, Gramespacher JA, Pance K, Rettko NJ, Solomon P, Jin J, Lui I, Elledge SK, Liu J, Bracken $\mathrm{CJ}$, et al. Bispecific $\mathrm{VH} / \mathrm{Fab}$ antibodies targeting neutralizing and non-neutralizing Spike epitopes demonstrate enhanced potency against SARS-CoV-2. MAbs 2021; 13:1893426.

26. De Gasparo R, Pedotti M, Simonelli L, Nickl P, Muecksch F, Cassaniti I, Percivalle E, Lorenzi JCC, Mazzola F, Magrì D, et al. Bispecific IgG neutralizes SARS-CoV-2 variants and prevents escape in mice. Nature 2021; 593:424-8.

27. CDC. COVID Data Tracker. Available from: https://covid.cdc.gov/covid-data-tracker/\#variantproportions 
bioRxiv preprint doi: https://doi.org/10.1101/2022.01.04.474803; this version posted January 4 , 2022. The copyright holder for this preprint (which was not certified by peer review) is the author/funder, who has granted bioRxiv a license to display the preprint in perpetuity. It is made available under aCC-BY-NC-ND 4.0 International license.

28. Yuan TZ, Garg P, Wang L, Willis JR, Kwan E, Hernandez AGL, Tuscano E, Sever EN, Keane E, Soto C, Mucker EM, Fouch ME, Davidson E, Doranz BJ, Kailasan S, Aman MJ, Li H, Hooper JW, Saphire EO, Crowe JE, Liu Q, Axelrod F, Sato AK. Rapid discovery of diverse neutralizing SARS-CoV-2 antibodies from large-scale synthetic phage libraries. MAbs. 2022 Jan-Dec;14(1):2002236. doi: $10.1080 / 19420862.2021 .2002236$.

29. Hastie KM, Li H, Bedinger D, Schendel SL, Dennison SM, Li K, Rayaprolu V, Yu X, Mann C, Zandonatti M, et al. Defining variant-resistant epitopes targeted by SARS-CoV-2 antibodies: A global consortium study. Science 2021; 374:472-8.

30. Alaa Abdel Latif, Julia L. Mullen, Manar Alkuzweny, Ginger Tsueng, Marco Cano, Emily Haag, Jerry Zhou, Mark Zeller, Emory Hufbauer, Nate Matteson, Chunlei Wu, Kristian G. Andersen, Andrew I. Su, Karthik Gangavarapu, Laura D. Hughes, and the Center for Viral Systems Biology. Omicron Variant Report. outbreak.info; Available from: https://outbreak.info/situation-reports/omicron

31. Bentley EG, Kirby A, Sharma P, Kipar A, Mega DF, Bramwell C, Penrice-Randal R, Prince T, Brown JC, Zhou J, et al. SARS-CoV-2 Omicron-B.1.1.529 Variant leads to less severe disease than Pango B and Delta variants strains in a mouse model of severe COVID-19. bioRxiv 2021; 2021.12.26.474085. Available from: https://www.biorxiv.org/content/10.1101/2021.12.26.474085v2

32. Lucas, C., Vogels, C.B.F., Yildirim, I. et al. Impact of circulating SARS-CoV-2 variants on mRNA vaccine-induced immunity. Nature 600, 523-529 (2021). https://doi.org/10.1038/s41586-021-04085-y

33. https://www.fda.gov/media/145802/download

34. https://www.regeneron.com/downloads/treatment-covid19-eua-fact-sheet-for-hcp.pdf 